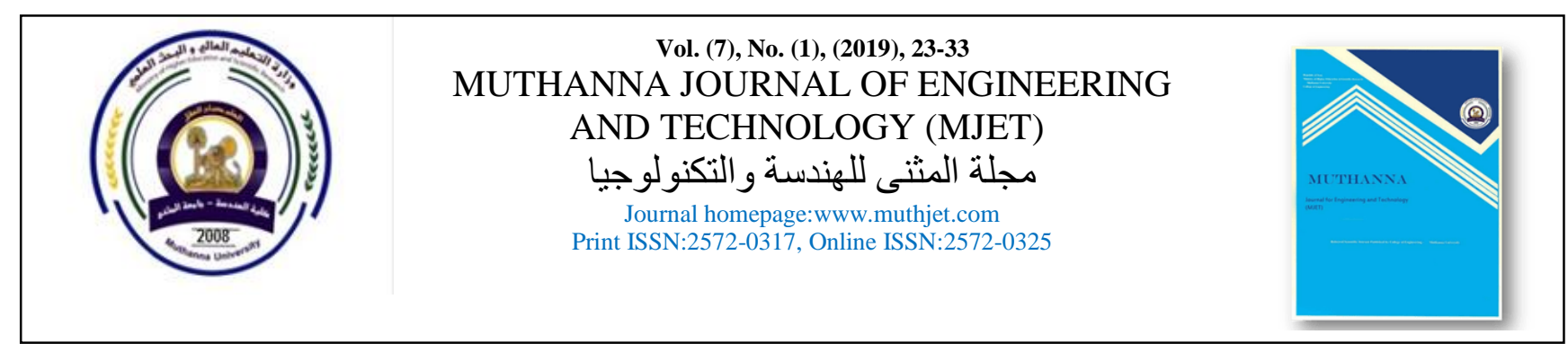

\title{
Relevance the architectural formation with the properties place
}

\section{Hamid Ali Abed Almousawi, Dr. Mustafa kamil Alkhafaji.}

\author{
Al-Shanashil-Baghdadiya as a case study
}

ARTICLE INFO

Received: 27/03/2019

Accepted: 26/05/2019

Keywords

visual perception، formal relevance‘Privacy of place

\begin{abstract}
:
The relevance is a strategy to express the privacy of the place' and that architecture uses shapes to reflect the objectives of the building، Activating the distinctive role of the architecture that associated with the site. which includes the physical space، shape and place's space during the global challenges of attempts to obliterate the environmental ' historical and cultural differences، which necessitated the balance between man and the environment ، Therefore ، the research's problem was to identify as "a lack of knowledge about the effect of place specificity on the architectural structure." The objective of the research was to highlight the construction of a theoretical framework that helps designers to produce relevance ally of the buildings. The research hypothesis is based on the descriptive analysis approach in constructing a cognitive framework for the concept of formal relevance and extracting the most important vocabulary and special indicators ، then applying them within the study. The study concluded by analyzing a group of local historical buildings in the city of Baghdad. The study concludes with "building a model that demonstrates the effect of place's characteristics on architectural formation and its relation to place." The results of the analysis showed that formal relevance contributes to the development and growth of the building's integration with the environment Surround it.
\end{abstract}




\section{Introduction:}

The study discussed the definition of concepts of relevance, configuration and place, through build a global understanding of those words, through the first two topics that will deal with the language and terminology and in other literature, develop the appropriate definitions, while the second topic will discuss the three vocabulary searching in the architecture and up to the abstract definition of each article. The importance of the formal aspect has been determined the field of research in the formal relevance between the architectural configuration and place. The research aims to "shed light on the construction of a theoretical framework that helps designers to produce buildings that are relevance ally compatible with the place." Figure (1) shows the path that will follow the research to achieve the mentioned above.

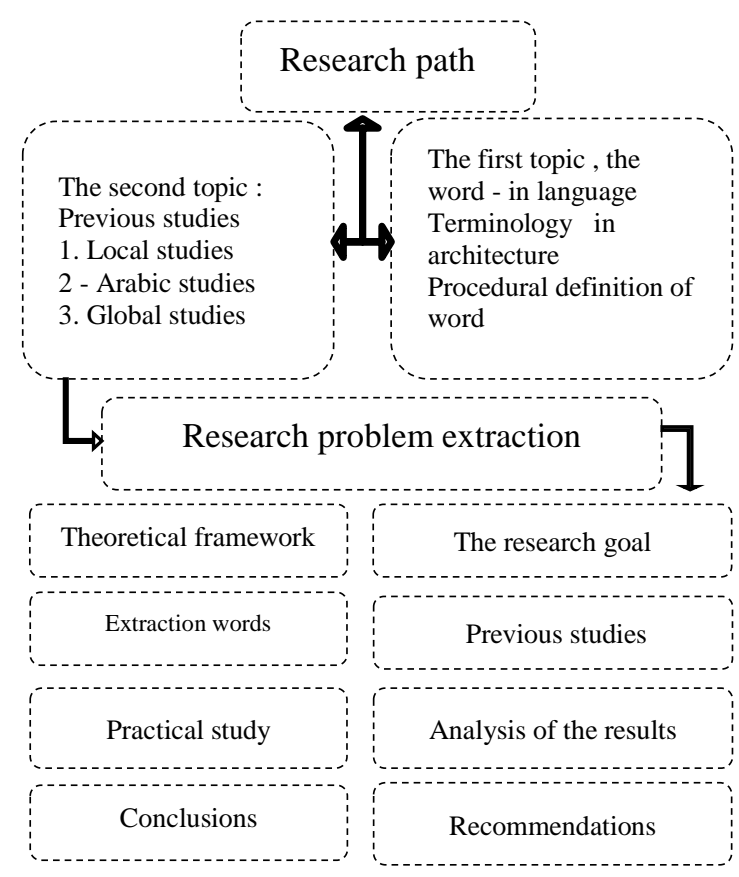

Figure (1) shows the research path (preparation of researchers)

\section{2: fundamental concepts in research \\ 1. The relevance:}

A -The relevance in both language and terminology: The Arabic dictionaries agree that the relevance is derived from a word that corresponds to suitability and the problem. It is said that it is appropriate and to be convenient for. as well as twins

if birth two in same time from two and up ${ }^{1}$, so the word derived from coincide under the term "relevance" in English, which came in a dictionary in the sense of malformation, compatibility,
2

consistency, relevance . By addressing the concept of adaptability in language, linguistic alignment can be defined as "conforming and reforming the external form of the object, by an external stimulus leading to a better approach towards the better, and 3 a closer approach to the accepted nature." Piaget has defined the relevance as an organizing process linked to the concept of adaptation In the individual, ie the process that preserves the balance between assimilation and appropriateness while interacting together $^{4}$.

$\mathrm{B}$ - The relevance in architecture: Physical means the degree of consistency of elements of urban 5

design in the general configuration . The practical benefit of the building is the relevance, which is always present before the building itself and the original cause and quality, which is the predominant purpose and the main source of influence on the design and taking the building as it. Accordingly,

practical alignment can be defined as: a strategy .

2- The Formation

A - The Formation in linguistic and terminology: Arabic dictionaries: - Formation (basic verb form). Formation of the scene: create the image, form the

word: -: accurate its characters in the movements . A-Formation - shaping, create a structure, BFormation, invent, installation in terminology: Formation is mainly due to the arts that form (or are made up of forms where the original derivation of the word The Word Plastics, which in Greek terms means sculpture, architecture, or the art of making models or statues, and for each process a product is also called formation, so the word formation in Arabic and English is called the process and the product.

B - Formation in architecture: a man deals during his life with a series of formations either aesthetic simulates the sense and taste, or utilitarian to perform a particular job, or formations that integrate the concept of utilization and beauty, architecture as an applied shroud connect to the purpose of use is a fictional vacuum sheltering a certain human activity 8

And aims to perform a certain benefit . a big number of the previous or current buildings have been connected to the human mind through its distinctive and unique formations. As well as the formation of the building is concerned with new images and ideas, it is also a motive for the human's mind to assimilate this composition. So that, the formation was the expression of the identity of the building and its uniqueness amidst the large number of buildings ${ }^{9}$. The architectural design can be defined as "linking a group of elements according to the principles and 
rules of architecture to form a product that expresses the needs of man".

\section{The Place:}

A - A place in linguistic and terminology: It appears in the Arabic dictionaries: The word place in the Arabic language referred to the deeper sources, and perhaps to Sumerian, in the interpretation of the book of Ragheb Al-Isfahani $502 \mathrm{AH}$. In the foreign lexicons, the word place is a place, a domicile, a

house, a degree ${ }^{1}$. The word has repeated itself : site , house, place. As for the term: place is the space containing formulas of forms dictate the norms and orientations of intellectual and sensory feelings and influential place in the souls is able to convey all those feelings and dictates the human subconscious

system and its evolution ${ }^{1}$. The place is the material of the form if it is built, and it settles in its formation $^{1}$. Schulz ${ }^{1}$ points out that ${ }^{2}$ the place represents man's relationship to the perceived phenomenon, and its relation to the constituent elements of identity. Through these relationships, man begins to adapt to his environment and to discover the characteristics of that environment.

B - The place in architecture: The concept of place is a basic specialty in all areas of physics, sociology,

economics, politics, architecture, art ... etc ${ }^{1}$. For example, sociologists show that the methods of giving meaning to a place depend on culture, civilization and the surrounding environment that

strongly influence human behavior and values . This place generally surrounds the existence of man and is constantly held and depends entirely on the

surrounding and must be shaped elements ${ }^{1}$. The place as an idea means the intangible limit of our vision of form or place and distance arises the

relative relations between the physical objects ${ }^{1}$

During the twentieth century architectural movements worked to strengthen the bonds of linking the place with the bonds of form and that modern views depict the place and form in balance,

a way expressed in the theory of unity spatial ${ }^{1}$. So that, the place can be defined as "the container of the building with its physical dimension, and the resulting environment depending on the surrounding environment, is organized according to rules expressing mutual compatibility and influence.") .

2.1.1: Al-Shanashils, the single word is Shanashil which is the part of the building's wall thickness, which overlooks the outside, or the middle courtyard, reflecting the aesthetic, social and heritage value of the building, and its system offers several benefits to the existing place.

1.2.1: Characteristics of the place: The characteristics of the place mean the physical environment surrounding the building, which includes the physical boundaries of the place, the shape of the place, its area and its structure, and the boundaries, the concrete limit that starts from another place.

\subsection{1: Previous studies on relevance.}

\section{1- Local studies}

A - Al-Asadi study, Asaad, "Knowledge of the place" $2016^{1}$ : The study discussed mainly the concept of relevance by referring to the term "division and belonging" familiarity and ophthalmology between the building and its place. " familiarity has a role in building the knowledge of the place as an event not only of architecture, but of the knowledge that makes us live the place as we 1 live." It also referred to the dimensions and characteristics of the physical place, and its role in the production of the building. "The building is not simply placed in the place, but it is produced by the place and gives birth." The study also confirmed the close relationship between the site and the shape of the building, because it is difficult to reach the shape of the building without knowledge of the site "It is rare to reach the architects of the forms of their buildings, before choosing the place and determine the pattern of employment, We conclude from the study that it is almost impossible to reach the shape of the building, Without recognition of the place and natural characteristics, represented by the climate and water and topography of the site and the eyesight, etc., that is, when the building is aware of the place that operatess and surrounds, arrive at the uniqueness, and this is the result of the mutual effect between the form of building and the place is nominative in the search relevance .

B - The study of Al-Jadirji, raised "problematic architecture and theoretical theory" $1988^{2}$

Al-Jadraji mentioned in his study (the problem of architecture and structural theory): Adaptation as a utilitarian need among the three needs he mentioned (utilitarian need, symbolic necessity and need). The need for utilitarian requirements : This provides for basic survival requirements such as shelter, storage, The functions of the house, the castle, the chair, the wagon and the sword. "I began to learn from traditional construction and try to relevant traditional forms with the inevitable presence of modern technology. My goal was to create an architecture that is consistent with the spatial reality that is being built, and that it is not allowed to sacrifice a substantial amount to the advantage of modern technological capabilities. We are interested in understanding and analyzing the existing thinking in traditional methods of nature control and light reflections. We conclude from the study that the alignment was linked to the benefit (function), and the relevance is to create a balance between modern technology and the core values of the place through 
a call to relevance between traditional forms and technology.

\section{2- Arabic studies}

A-Fayyad, Rahif's Study "Architecture and Awareness of Place, $2004^{2}$ :

The study refers to the relevance in architecture and describes it as a product and reflection of the response to the climatic and geographical data, which is achieved through the use of cashers, shaded shaded balconies, good guidance and the use of some local materials, all of which remain within geography rather than social content. The study also refers to the role of the place and is considered as a maker of the architectural form of the building, and the place where the study study is the geographical environment. The study also describes the architecture of Mohammed Makiya and Rifat alJadirji as "in place and place and people this place"The first describes that he tried to invent a different language for a historical architecture that is always in keeping with the principles of modernity, while describing the style of the second, In the style of pasting and borrowing of its architecture from the elements of traditional architecture. The study considers the place as equal to the natural place. We conclude from the above that the study considers the place is the architect of the building, The place is the nature of the site, which includes geography, topography and climate.

B - Ibrahim Abdul Baqi 's study, "Building architectural thought and design process" $1987^{2}$ :

The study suggests that adaptability in architecture is a process of formal linking between theory and reality through elements and relationships. The reality here is the realistic understanding of the environmental, civilizational and social aspects in which the architecture associated with the place grows. This connection is embodied through materials, construction methods, place characteristics, and assimilation of the design values of spatial architecture. The study also indicates that some of the buildings that were built without an architect were a reflection of society, and a way of dealing with natural and social conditions, that the external architectural configuration was a reflection of the climatic and cultural characteristics associated with the place. We conclude from the study that it is the relevance of the foundations of design, and it leads to the integration of the building through architectural interfaces linked to environmental and cultural values.

\section{3- The foreign studies :}

A- The study of Funish, Linda Papas "Amman New Dawn ( relevance of Authenticity and Contemporary), $2016^{2}$ : The study refers to the alignment with the natural through interaction with the geography of this country, Which is characterized by the diversity of the topography of the mountains and rivers and plateaus and rivers, where the geographical as a must to deal with and try to adapt to serve the human, that the terrain unique from any place in the world, so contributed to the 1 production of buildings unique and compatible with the environment and culture of the place, as the study indicates the importance of understanding the history of the place, inspired vocabulary and considered the source of form patterns acceptable because they are linked to the culture of society. We conclude from the study that alignment is how to deal with the natural as an object, as a source of beauty.

B- K.W Smiths, Foundations of Design in Architecture, $2012^{2}$ :

The study refers to the concept of relevance on the overall relationship between the building and its surroundings in terms of place, As expressed by the following appearance after unity, Where it is considered that the site despite the Kuna outside the building, but is within the sphere of the impact of the

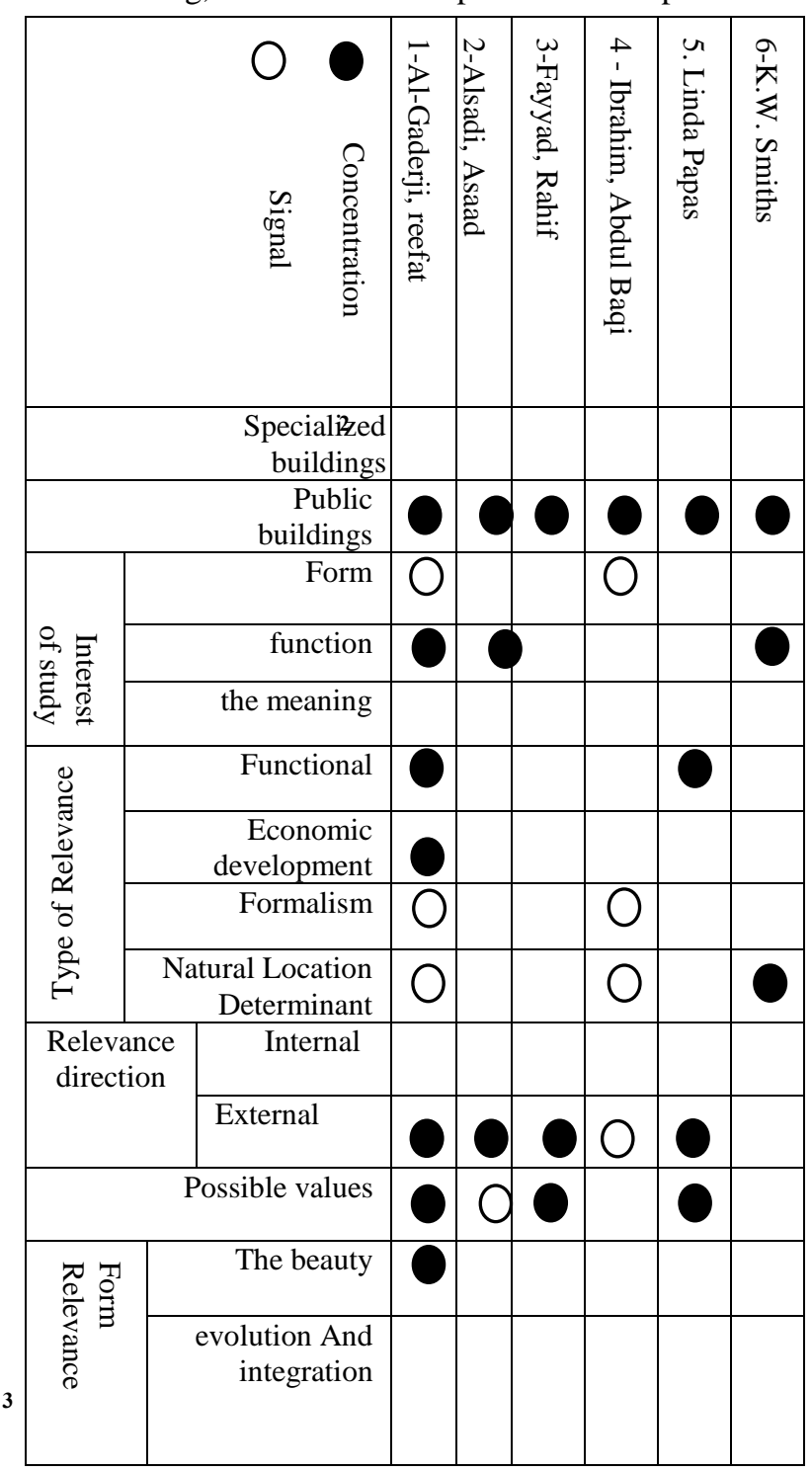

building and must be considered part of the overall visual configuration and describes the alignment of this vital relationship, which is similar to the vitality 
of the building itself, It is cited in several examples, such as the Japanese architecture and the traditional English country house, which combines these regular buildings composition and natural automatic content, Finally, the study indicates that the lack of interest in formal relevance in recent years is due to expressive reasons. We conclude from the study that it emphasizes the relationship with the ocean as the most extensive, ie, the relevance of the relationship of the part to the whole.

From the above, we conclude from the above table that the formal alignment that leads to the evolution and integration of the form is one of the least addressed in the studies, so this was one of the reasons for the emergence of the research problem.

Table (2) shows a mechanism or focus on the previous studies (preparation of the researchers).

\subsubsection{Research problem:}

After the previous paragraphs in the most significant studies that linked the characteristics of the place architecture and the reflection of those characteristics in the form of buildings and their role in highlighting the beauty of the building, we also note our lack of a specialized study,

Since all the previous studies dealt with public buildings. As we have noted that most studies are concerned with the functional aspect and functional alignment while ignoring the relevance of the shape of the building with the characteristics of the place .Accordingly, the general problem of research can be determined by ((there is a lack of knowledge about the effect of place characteristics on the facades of buildings).

A - Determination of research objectives:

After identifying the research problem, the main objective of the research must be determined

Which is to "build a theoretical framework that helps designers to produce buildings that conform to the characteristics of the city of Baghdad as a city with a distinct character."

Which is reached through secondary goals:

First: To reach conclusions on the formal relevance and determine the relationship between the characteristics of the place and architectural configuration and relation to the place ( Baghdad city ).

Second: to know the relationship of architectural formation to the place through examples in Baghdad city .

B - Theoretical framework of the concept of formal relevance :

In this paragraph, we will clarify and showing a range of architectural studies that are very close to the research framework.To solve the research problem as provides the basic vocabulary through which the different aspects of the research problem are measured. the preparation of practical application requirements through the selection of samples of the facade of a number of buildings to be applied to the scale, and to identify the vocabulary and variables of measurement and determine the methods of measurement and astrology and the construction of basic and secondary research hypotheses, extract and analyze the results of practical application of research, then put forward conclusions, and finally put forward the final conclusions.

\subsection{2: Previous studies on formal relevance :}

1. The study of Nicholas, Salingaros, "Unified Architecture Theory" $2017^{2}$ :

The study examined the distinction between the superficial appearance of organic composition,

And the generation of architectural forms according to the same processes that generate biological forms, and the possibility of understanding how the building appeared and how to interact and communicate with the surrounding. The theory relies on two paths: the pattern (based on experience) and science (the scientific method is not related to a particular pattern). It also indicates that each traditional architecture has its own formality language, the language depends on the climate and local materials. So that, we find the relevance of architecture with its formal language and its mixture with the typical language as well as all the traditional languages developed .. Emphasizes the study on the use of patterns being tested and accepted collective acceptance. Also the local measurement is done through the use of local materials and the extent of respect for place and nature, in the engineering of the building.

2. The study of Philip, Wilkinson, Great Buildings "" D.K, London, $2017^{2}$ :

The study shows through 53 reviews of various buildings in the world through history, which came in a variety of places, in terms of geography and in terms of customs and traditions, which contributed to the production of different styles of architecture, and various personalities of spatial architecture. The study also refers to the principle of the whole, where you find that the building must be seen as a whole, through the shape, as referring to the principle of the part, and by understanding the parts of the building, We can appreciate it as a whole through its history and its sheer use of space and shape, the details are unique and unique. The study also discusses the concept of visual perception and a cycle in understanding and absorbing the building, through the dominance of the building on the site or the merger of the building with the site, through the shape of the building as it embraces the earth or rises in it. The study also refers to the concept of rebalance in the building on the site. 


\begin{tabular}{|c|c|c|c|}
\hline Possible values & Secondary item 2 & $\begin{array}{l}\text { Secondary } \\
\text { item } 1\end{array}$ & $\begin{array}{l}\text { The main } \\
\text { item }\end{array}$ \\
\hline Exploitation of nature of the site & $\begin{array}{l}\text { Effect of the environment in the } \\
\text { building }\end{array}$ & \multirow{3}{*}{$\begin{array}{l}\text { Response } \\
\text { to climate } \\
\text { variables }\end{array}$} & \multirow{10}{*}{$\begin{array}{l}1 \text { - the } \\
\text { effect of } \\
\text { climate } \\
\text { variables } \\
\text { of the } \\
\text { place on } \\
\text { the } \\
\text { formation } \\
\text { of } \\
\text { structural } \\
\text { nature }\end{array}$} \\
\hline $\begin{array}{l}\text { Exploitation of relations with } \\
\text { neighborhoods }\end{array}$ & $\begin{array}{l}\text { The mutual influence between the } \\
\text { building and the environment }\end{array}$ & & \\
\hline The ideal orientation & Effect of building in the environment & & \\
\hline Shape, size and area of openings & $\begin{array}{l}\text { The existence of alternatives and } \\
\text { solutions harmful to the environment }\end{array}$ & \multirow{7}{*}{$\begin{array}{l}\text { Neglect of } \\
\text { climate } \\
\text { variables }\end{array}$} & \\
\hline Softness and roughness in the walls & \multirow{6}{*}{$\begin{array}{l}\text { The existence of alternatives and } \\
\text { solutions that are not harmful to the } \\
\text { environment }\end{array}$} & & \\
\hline $\begin{array}{l}\text { Exploitation of renewable energy } \\
\text { sources }\end{array}$ & & & \\
\hline Form Fonts & & & \\
\hline Colors & & & \\
\hline Terrain & & & \\
\hline Use of local materials & & & \\
\hline Walls & Compatibility with the Ocean & & \multirow{9}{*}{$\begin{array}{l}\text { 2-Effect of } \\
\text { spatial } \\
\text { visual } \\
\text { perception } \\
\text { on the } \\
\text { shape of } \\
\text { the } \\
\text { building }\end{array}$} \\
\hline Decorative elements & Contradiction with the ocean & & \\
\hline Materials of termination & $\begin{array}{l}\text { There is a relationship between the } \\
\text { building and the place }\end{array}$ & & \\
\hline Texture & $\begin{array}{l}\text { There is no connection between the } \\
\text { building and the place }\end{array}$ & & \\
\hline Shapes & Existence of previous experiences & \multirow{5}{*}{$\begin{array}{l}\text { Interactive } \\
\text { perception }\end{array}$} & \\
\hline the scale & Lack of previous experience & & \\
\hline Context & $\begin{array}{l}\text { Appropriate to the intellectual } \\
\text { background }\end{array}$ & & \\
\hline Diversity & \multirow[t]{2}{*}{ Counters the intellectual background } & & \\
\hline merger & & & \\
\hline
\end{tabular}

3 - The study of francis D. Kching, Architecture is Form, space and order "" translation by Ahmed Khatib, $2016^{2}$.

This study detailed the rebalance or compatibility with the environment as one of the most important components of the architectural system, which includes place, environment, climate, sun, wind, heat, geographical place, topography, soil, plants, water. The study dealt with the concept of visual perception and a course in understanding architectural forms. If our understanding and understanding of how we create an interaction between positive and negative elements within a galaxy, where the positive elements represent the image while the negative represents the background, that we have to be aware of the fact that the forms or positive elements that attract our attention cannot be understood only through the contrast is the background, they will be a fact does not break, the unity of opposites, just like the elemental composition and the place of the two are real architecture. the study also refers to the human scale, which must be taken into consideration and carefully, whether the building has the role of completing the existing fabric somewhere.

4. The Study of Bares Raffaelli, "The Fast Guide to Architectural Form" 2016 ": The study "Quick Guide to Architectural Model"

There are sixty different basic models of architectural models with sketches and pictures of models applied in buildings, which is a very practical guide to the basic forms of planning and architectural design, in which Eisenman defines the shape as the visual appearance of the building (Line, outline, shape, composition), that including a line or an outside line (frame), The form is either expressive of the function or intended to focus on certain ideas. This study also indicates the percentage of surface area openings, which requires a condition of equivalence between the solid and open, although it indicates that the superiority is in favor of solid, with

different percentages depending on the type of project and surrounding environment.

The study also focused on the shape of openings which must be coincide with the structural structure and the way of formation, as well as the study refers to the concept of deformation that affects the forms, resulting from deletions and additions, which are confirmed to be in accordance with future use.

\subsection{2: Abstract of studies:}

The previous studies clarified many of the key words on which they have focused, the secondary vocabulary and its possible values, which represent the conceptual frame, thus, the research has achieved its first goal in building a theoretical framework for formal relevance between the architectural form and the specificity of the place, the vocabulary came as follows: 
Table (3) All the elements of the general theoretical framework. Prepared by (the two researchers).

A - The practical study:

In the practical study, the vocabulary derived from the theoretical framework will be applied to a selected group of samples (The effect of climate variables of the place on the formation of structural nature, the impact of spatial perception of spatial shape of the building) .

B - The test hypothesis research:

This research was based on the main hypothesis (The architectural configuration corresponds to the characteristics of the place through the climatic contains a detailed explanation of each secondary variable within the specific adjustment vocabulary, the two components (the effect of climatic variables on the place on the formation of structural character) and (the impact of spatial perception of spatial shape of the building) the analysis was done within the form (1) that shows how the possible values will be variables and the visual perception of the product). The research was according to a comparative analytical descriptive measurement based on analysis of detailed explanatory texts, drawings and illustrative charts of a number of selected projects, the analysis included several stages:

First: A general description of the project based on the sources and re-analysis of each project according to the specific vocabulary for the measurement and the descriptive charts and illustrations. Second: The professional clarification and measurement form determined depending on the nature of the relationship between each of the selected terms and the secondary indicators as stated in the form, which were later applied to the selected samples, based on information obtained from the examples of each of the selected projects, and in line with the research objective.

\begin{tabular}{|c|c|c|c|c|c|c|c|c|c|}
\hline \multirow[b]{2}{*}{ 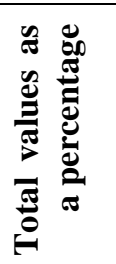 } & \multirow{2}{*}{$\stackrel{\tilde{\sigma}}{\tilde{\theta}}$} & \multicolumn{6}{|c|}{ Possible values for the three samples } & \multirow{2}{*}{$\begin{array}{l}\text { Secondary } \\
\text { variables }\end{array}$} & \multirow{2}{*}{$\begin{array}{r}\text { Key } \\
\text { variables }\end{array}$} \\
\hline & & 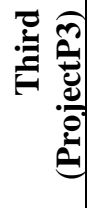 & 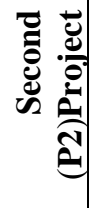 & 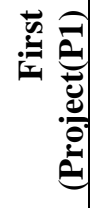 & & & & & \\
\hline $92 \%$ & 11 & $r$ & $\varepsilon$ & $\varepsilon$ & \multicolumn{3}{|c|}{ Exploitation of nature of the site } & \multirow{6}{*}{$\begin{array}{l}\text { the climate } \\
\text { (A1) }\end{array}$} & \multirow{10}{*}{$\begin{array}{l}\text { The Effect } \\
\text { of Climate } \\
\text { Variables } \\
\text { on the } \\
\text { Place on } \\
\text { Structural } \\
\text { Formation } \\
\text { (A) }\end{array}$} \\
\hline $83 \%$ & 1. & $r$ & $\varepsilon$ & $r$ & \multicolumn{3}{|c|}{$\begin{array}{l}\text { Exploitation of relations with } \\
\text { neighborhoods }\end{array}$} & & \\
\hline $92 \%$ & 11 & $r$ & $\varepsilon$ & $\varepsilon$ & \multirow{2}{*}{\multicolumn{2}{|c|}{$\begin{array}{l}\text { The ideal orientation } \\
\text { Shape, size and area of } \\
\text { openings }\end{array}$}} & Light, & & \\
\hline $83 \%$ & 1 . & r & $\varepsilon$ & $\varepsilon$ & & & $\begin{array}{r}\text { wind } \\
\text { and heat }\end{array}$ & & \\
\hline $\mathbf{8 3 \%}$ & 1 . & $r$ & $\varepsilon$ & $r$ & \multicolumn{3}{|c|}{$\begin{array}{l}\text { Softness and roughness } \\
\text { in the walls }\end{array}$} & & \\
\hline $83 \%$ & 1 . & $r$ & $r$ & $\varepsilon$ & \multicolumn{3}{|c|}{$\begin{aligned} \text { Exploitation of renewable energy } \\
\text { sources }\end{aligned}$} & & \\
\hline $67 \%$ & 8 & r & r & $\varepsilon$ & $\begin{array}{l}\text { Surface of } \\
\text { soil form } \\
\text { lines }\end{array}$ & $\begin{array}{l}\text { Surface of } \\
\text { soil form } \\
\text { lines }\end{array}$ & $\begin{array}{l}\text { simulati } \\
\text { on }\end{array}$ & \multirow[t]{4}{*}{$\begin{array}{l}\text { Topography } \\
\text { (A2) }\end{array}$} & \\
\hline $75 \%$ & 9 & r & $\varepsilon$ & $r$ & Colors & & & & \\
\hline $83 \%$ & 1. & $r$ & $r$ & $\varepsilon$ & \multicolumn{3}{|l|}{\begin{tabular}{|l|} 
Terrain \\
\end{tabular}} & & \\
\hline $92 \%$ & 11 & $\varepsilon$ & $\varepsilon$ & $r$ & \multicolumn{2}{|c|}{ Use of local materials } & $\begin{array}{l}\text { Exploita } \\
\text { tion }\end{array}$ & & \\
\hline $92 \%$ & 11 & $\varepsilon$ & $\varepsilon$ & $r$ & \multicolumn{2}{|l|}{ Walls } & Formati & & \multirow{9}{*}{$\begin{array}{l}\text { Effect of } \\
\text { spatial } \\
\text { visual } \\
\text { perception } \\
\text { on the } \\
\text { shape of } \\
\text { building } \\
\text { (B) }\end{array}$} \\
\hline $83 \%$ & 1. & $\varepsilon$ & $r$ & $r$ & \multicolumn{2}{|c|}{ Decorative elements } & ve and & Elements & \\
\hline $92 \%$ & 11 & $\varepsilon$ & $\varepsilon$ & $r$ & \multicolumn{2}{|c|}{ Materials of termination } & characte & (B1) & \\
\hline $92 \%$ & 11 & $\varepsilon$ & $\varepsilon$ & $r$ & \multicolumn{2}{|l|}{ Texture } & ristic & & \\
\hline $83 \%$ & 1. & $\varepsilon$ & $r$ & $r$ & \multicolumn{2}{|l|}{ Shapes } & elements & & \\
\hline $100 \%$ & IT & $\varepsilon$ & $\varepsilon$ & $\varepsilon$ & \multicolumn{2}{|l|}{ the scale } & (B1-1) & & \\
\hline $100 \%$ & IT & $\varepsilon$ & $\varepsilon$ & $\varepsilon$ & \multicolumn{2}{|l|}{ Context } & & & \\
\hline $\mathbf{8 3 \%}$ & 1 . & $r$ & $r$ & $\varepsilon$ & \multicolumn{2}{|l|}{ Diversity } & & \multirow{2}{*}{$\begin{array}{l}\text { Relationshi } \\
\text { ps (B2) }\end{array}$} & \\
\hline $100 \%$ & IT & $\varepsilon$ & $\varepsilon$ & $\varepsilon$ & \multicolumn{3}{|l|}{ merger } & & \\
\hline
\end{tabular}

Table (1) represents the description and measurement form to measure the variables by determining values ranging from 0-0 (0: not verified, 1: weak, 2: acceptable, 3: good, 4: very good) And the percentages of the total variables.( Prepared by researchers).

C. Analyzing the results: 
This section includes a discussion and analysis of the results of the application derived from the measurement of variables on selected projects based on the program of the sports processor (Excel) in order to calculate the percentage of each variable in accordance with the election results, the results associated with the individual (the effect of climate variables of the place on the formation of structural character) and individual (the impact of spatial perception of spatial shape of the building) to the contrast between their indicators and their impact on formal relevance :
Where the effect of the individual indicators (the effect of climate variables on the place on the formation of structural nature) was different in the impact on the level of achieving formal relevance, where the index of use (local materials), (ideal orientation), (Exploitation of the nature of the site) the highest proportion of $6 \%$, while the facilitator came both (softness and roughness), (shape, size and area of openings), (exploitation of relations with neighborhoods) (Topography) (exploitation of renewable energy sources), (colors), (terrain) by $5 \%$ Finally, the index (form of lines) came at $4 \%$ As illustrated in Figure (2). 


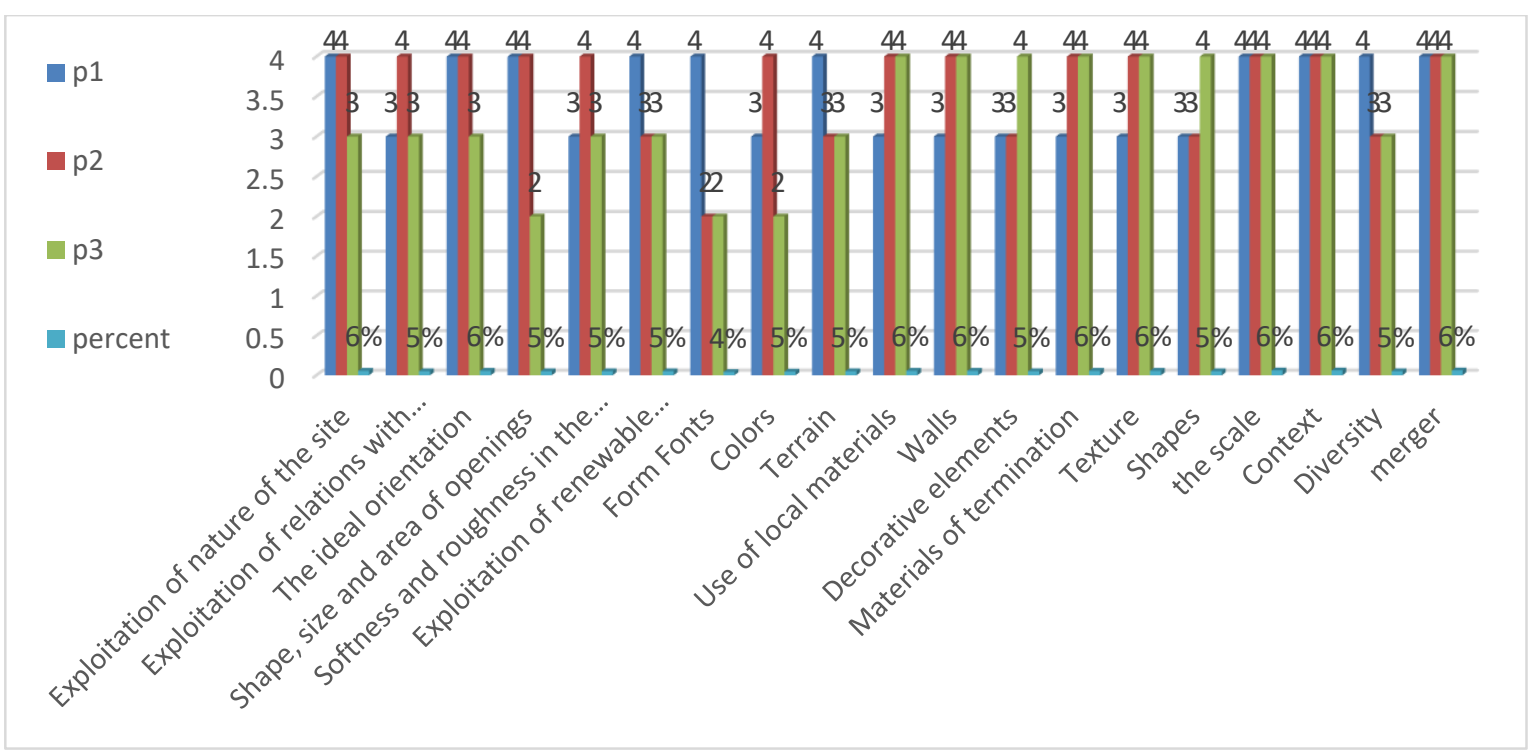

Figure (2): Analysis of the results of achieving the formal Relevance through a single (the effect of the climate variables of the place on the formation of structural character).

The effect of the individual indicators (the effect of visual spatial perception on the shape of the building) varied in effect on the level of formal Relevance. The index of the use of (integration), scale, context, texture, , While the index of (decorative elements), (shapes), (diversity) and exploitation of renewable sources of energy, (colors), (topography) by 5\%, as illustrated in Figure (2).

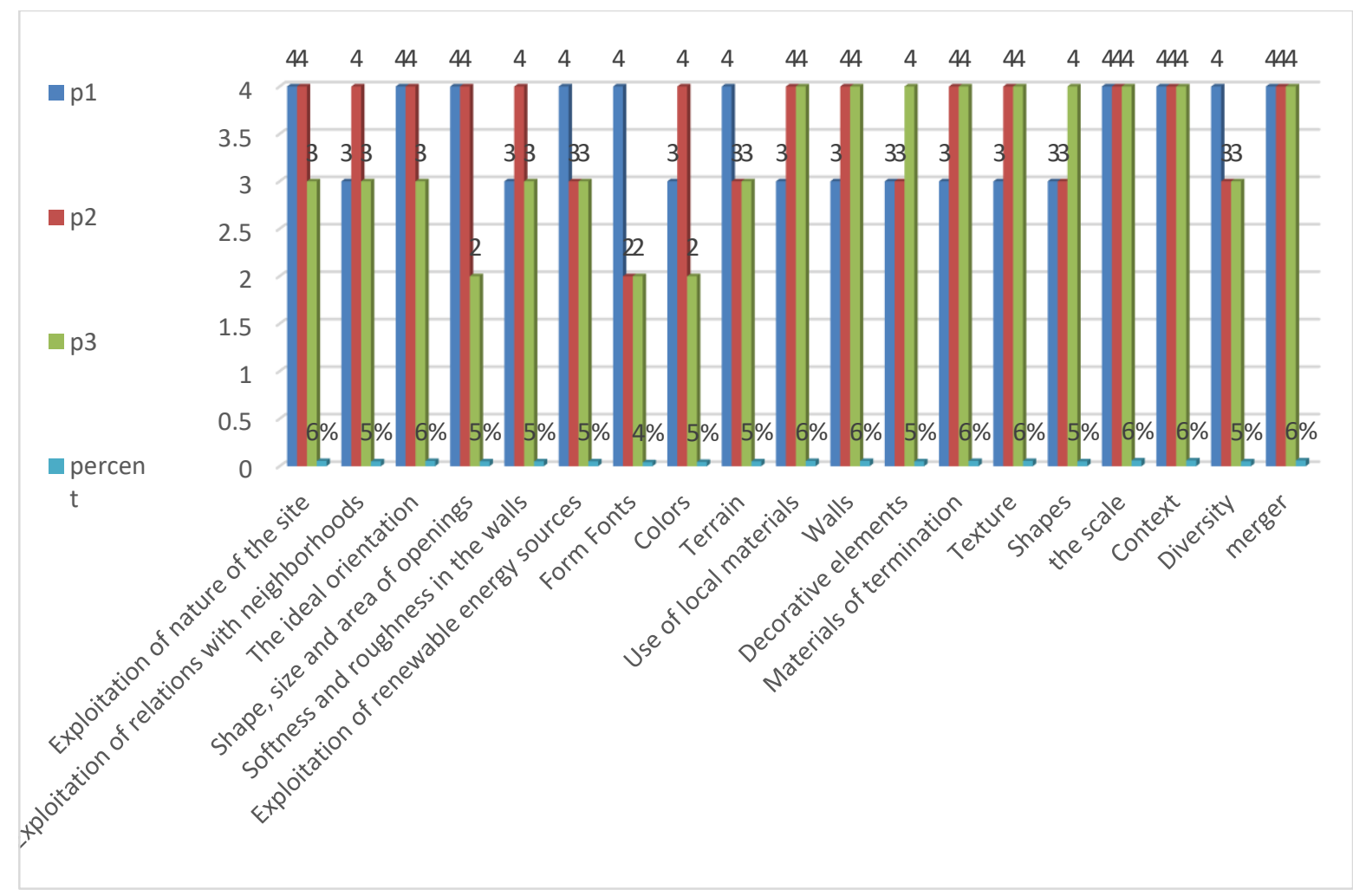

Figure (3) Analysis of the results of the formal Relevance through the single (the impact of climate variables of the place on the formation of structural character).

The percentage of the effect of the individual (the effect of climate variables on the formation of structural character) in achieving the formal Relevance by its indicators was $52 \%$, while the percentage of the effect of the other item (the effect of visual spatial perception in the form of the building), $48 \%$, according to the table (4) ). 


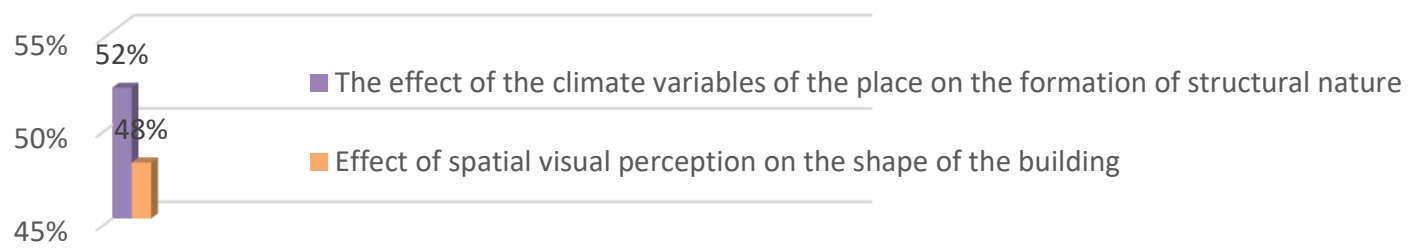

Figure (4) represents the percentage of the contribution of each individual in achieving formal Relevance.

Description of samples

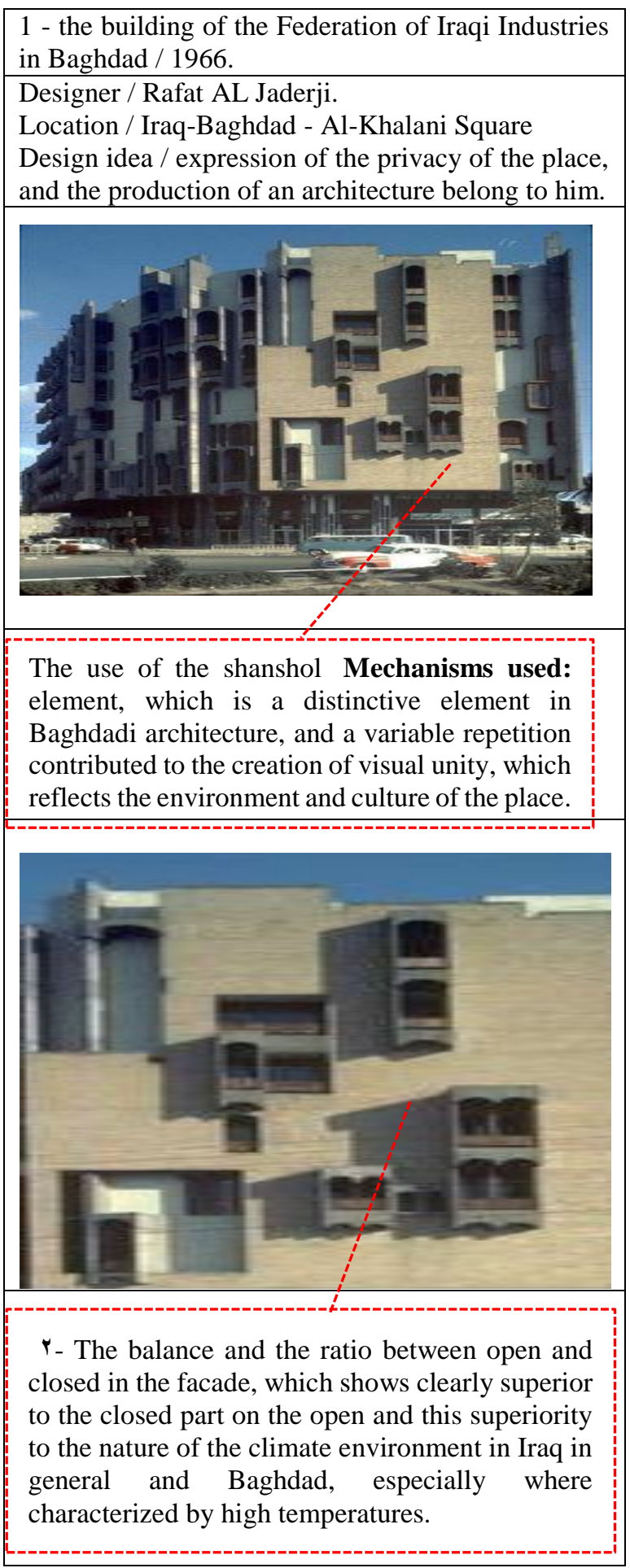

2 - the design of a residential project in Baghdad from (1992)

Project Name / Residential House

Designer / d. Saher al-Qaisi

Location / Iraq-Baghdad-Saidia

Design idea / harmony with the values of society in a modern way..

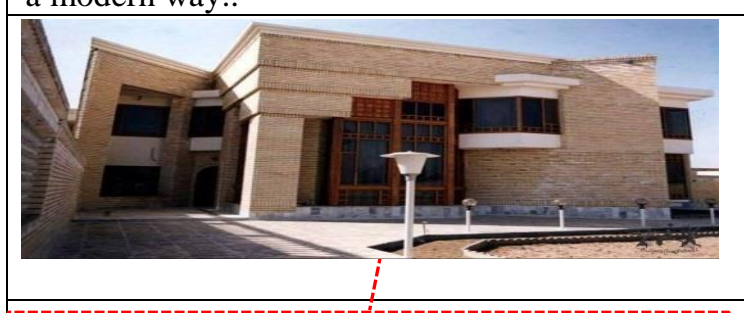

The use of local materials related to the specificity of the place, available locally such as wood, local bricks and cement concrete, as they relate to the background of theintellectual background of the recipient.

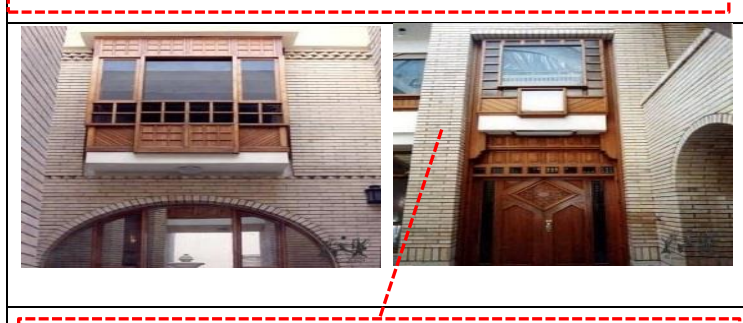

The balance between the open and the closed, taking into account the nature of the warm environment, in addition to the use of horizontal and vertical lines, straight and parallel, which is typified topography of flat flat areas, which distinguish the surface of the city of Baghdad.

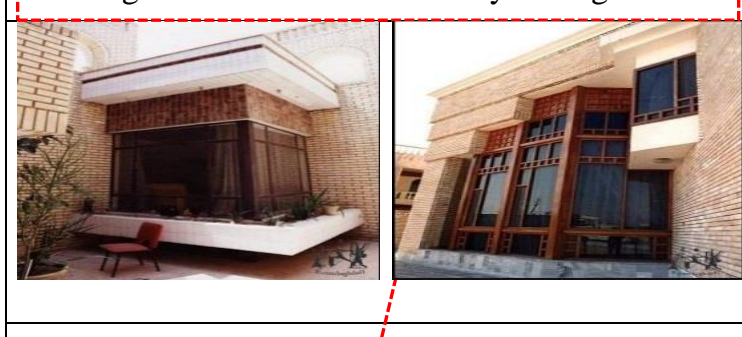

The production of the wooden chenille is modern and modern, by mixing traditional finishing techniques such as bricks and modern materials such as marble and stone. 


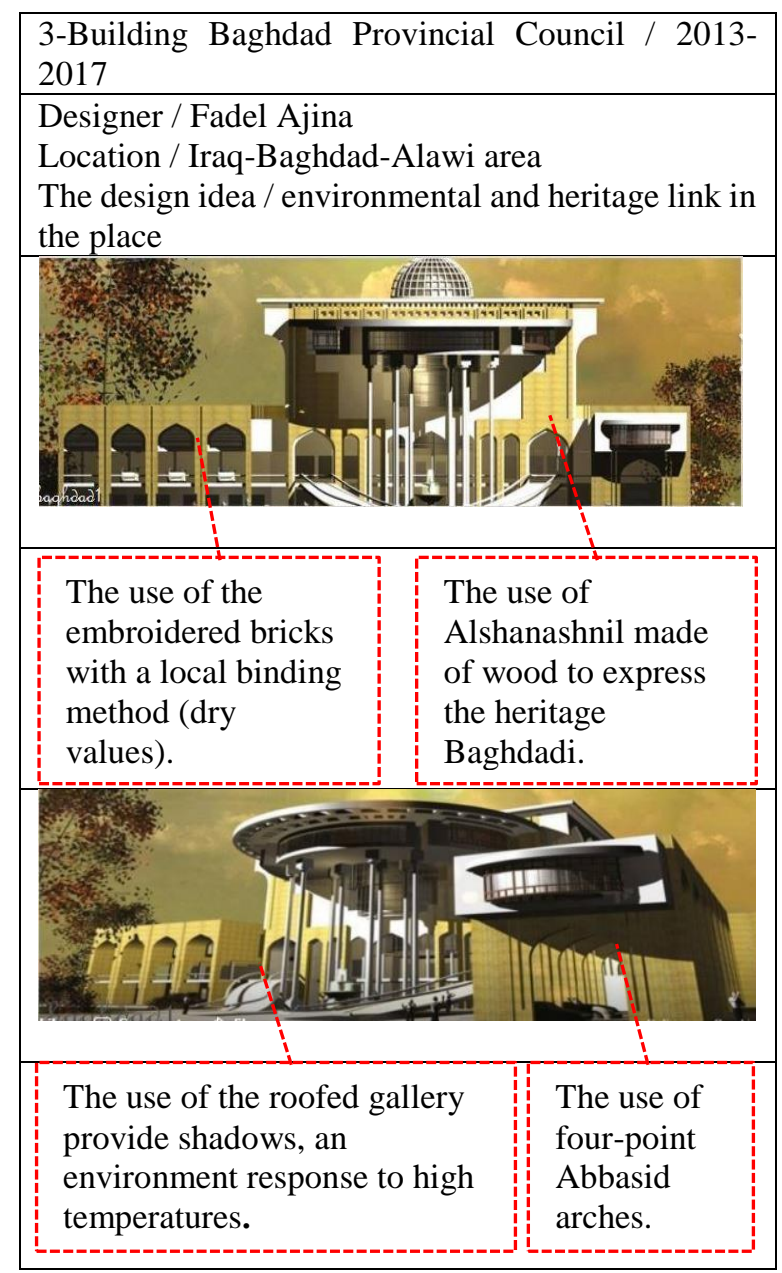

\section{Conclusions}

1. Relevance is a degree of difference, varying between congruence and contrast and not one of them.

2. The alignment is inversely proportional to the mental effort (the time taken to perceive and understand the shape) and linearly with the contextual effect.

3. The architectural form must be from a place that refers to a mechanism and not a form of production. 4. The determinants of the site such as climate and topography are laws that can not be tolerated in their implementation, because they stem from a composition that is in harmony with the nature of nature.

5. One of the most important reasons for the production of architectural facades that are incompatible with the place is the lack of laws or regulations that protect this approach and the low promotion to cultural and media. Also, the economic aspect that favors the job may be considered another reason for non-alignment.
6. There are constants and variables in determining the relationship between the architectural formation and the place where it became clear through the study that the constant such as the natural environment is a constant factor with the change of time, while the non-natural factors such as materials are changing factors over time, and affect each factor only fixed or variable Differently depending on the nature of the fixed or changing over time.

7. Formal alignment is a necessary criterion for the evaluation of the architectural product as well as the quality and creativity standards.

8. The formal alignment of the facades appears through the architectural elements of the façade. Formal alignment is the characteristic spatial character of the façade, as well as through the relationships that organize the elements, the most important being unity and diversity.

9. Reducing the objective of formal alignment on the attention curve may lead to negative results, where the drivers for the role of Relevance play an important role in determining the value of congruent actions.

10. Elements of visual composition: shape, color, texture have a direct impact on the formation of mental impressions and visual image of the external facades, and even constitute the basis of these mental images and the judgment and evaluation of the interface is closely related to the governance of these elements. 


\section{References}

${ }^{1}$ Ibn Manzoor, Muhammad Bin Makram, San'a Al Arab, Fourth Edition, C 15, Beirut, Dar Sader, 2005 , p. 140.

2 Almured,P414

${ }^{3}$ Jean Piaget (born August 9, 1896 - died September 16, 1980) was the eldest son of Swiss Arthur Piaget and French Rebecca Jackson. He was a Swiss psychologist and philosopher. Piaget is the leader of the construction school in psychology

${ }^{4}$ http://www.acofps.com/vb/showthrea d.php?t=24757)

5 Al-Anzi, Mohammed Bin Keman Fahad, Calibrated Urban Design for the Development of the Islamic Residential Environment, Islamic Foundations Symposium, 1991

${ }^{6}$ Al-Leithi, Hisham Mohamed Taher Ahmed, The Physiology of Architecture (Towards a Theory of Architectural Harmony in the Context of Islamic Reference Reference), unpublished $\mathrm{PhD}$ thesis, Cairo University, 2009, p. 51

${ }^{7}$ Dictionary: Rich, p. 52

${ }^{8}$ Raafat Ali, Triad of Intellectual Creativity, Form and Content, p 295.

${ }^{9}$ Wyane،William \&others, Architecture And you.P149.

1 Mounir Baalbaki, published By Abdel-Hafiz AlBassat, Beirut, 1978, p. 694.

1 Thawini, Ali, Place and Architecture, Egypt,: The Azhar Heritage Library, 2016, p23.

1 Asadi, Asaad, Knowledge of Place, First Edition, Syria: Nineveh House for Studies, Publishing and Distribution, 2016, p. 66.

1 Christian Norbert Schulz (May 23, 1926 - March $28,2000)$ is a Norwegian architect, teacher, and architect. One of his most famous works (existence, space and architecture).

1 Jammer'max'concept of 4 space;cambrige;Massachusetts;Harvard university press; P1،1969.

1 Tuan'yi-fu;space and place: the perspective of experience‘Edward Arnold(puplishers); limited university of Minnesota press; London ‘ united kingdom;1979،p5.

$1{ }^{1}$ Ching ، Francis D.K. ; ${ }^{6}$ Architecture : Form 'Space and Order ; Van Nostrand Reinhold ; New York ; U. S. A.; 1979 or 1996‘p108).

1 (Peterson ، Steven Kent ; Space and Ant:-Space ; The Harvard Architecture Review ; Vol.1 ; Spring ;1980 ; M.I.T. Press‘p15 ).

1 Porter، Tom ; The Architectưre's Eye;

Visualization and depiction of Spaec in

Architecture; Hon Kong ;1997،p84.

1 Asadi, Asaad, Knowledge oP Place, First Edition, Syria: Nineveh House for Studies, Publishing and Distribution, 2016

2 Al-Jadraji, Refaat, "The Problematics of Architecture and Structural Theory", The World of Thought, Volume 27, 2nd Edition, National Council for Culture, Arts and Letters, Kuwait. 1988.

2 . Fayyad, Rahif, Amarah and the Awareness of Place, Beirut: Dar Al-Farabi Publishing, 2004.

2 Ibrahim, Abdel Baki, Building Architectural Thought and Design Process, Egypt: Center for Planning and Architectural Studies, 1987.

2 Fanch, Linda Papas, Ammản Dawn of a New "Harmony between Originality and Modernity, Amman Press and Publication Foundation, 2016

2 Smithis, K., The Foundations of Design in Architecture, translated by Mohammed Ibn Abdul Rahman Al-Hussain: King Fahd National Library, Riyadh, 2nd edition, 2012.

2 Study of Nicholas, Salingarơs, "Unified Architecture Theory" translation (group members Twenty-two), 2017.

2 Study of Philip, Wilkinson, Great Buildings "" D.K, London, 2017.

2 Francis D.King, Architecture is Form, space and order" "translation of Ahmed Khatib, 2016.

2 Bares Raffaelli ${ }^{2}$ ،" The fast ${ }^{8}$ guid to Architectural Form “ $r, 17$. 